\title{
Sinapic Acid Inhibits IL-I $\beta$-Induced Apoptosis and Catabolism in Nucleus Pulposus Cells and Ameliorates Intervertebral Disk Degeneration
}

This article was published in the following Dove Press journal:
Journal of Inflammation Research

\author{
Jin-Feng Huang ${ }^{1,2}$ \\ Xuan-Qi Zheng ${ }^{1,2}$ \\ Jia-Liang $\operatorname{Lin}^{3}$ \\ Kai Zhang $\mathbb{B D}^{4}$ \\ Hai-Jun Tian (1D ${ }^{4}$ \\ Wen-Xian Zhou ${ }^{1,2}$ \\ Hui Wang ${ }^{1,2}$ \\ Ze Gao ${ }^{5}$ \\ Hai-Ming Jin ${ }^{1,2, *}$ \\ Ai-Min Wu (D) ${ }^{1,2 *}$ \\ 'Department of Orthopaedics, The \\ Second Affiliated Hospital and Yuying \\ Children's Hospital of Wenzhou Medical \\ University, Wenzhou, People's Republic \\ of China; ${ }^{2}$ The Second School of \\ Medicine, Wenzhou Medical University, \\ Wenzhou, People's Republic of China; \\ ${ }^{3}$ Department of Orthopaedics, Peking \\ University Third Hospital, Beijing, \\ People's Republic of China; ${ }^{4}$ Department \\ of Orthopaedics, Ninth People's Hospital, \\ Shanghai Jiaotong University School of \\ Medicine, Shanghai Key Laboratory of \\ Orthopaedic Implants, Shanghai, People's \\ Republic of China; ${ }^{5}$ Department of \\ Orthopaedic Surgery, The Third Hospital \\ of Hebei Medical University, Shijiazhuang, \\ People's Republic of China
}

*These authors contributed equally to this work

Correspondence: Ai-Min Wu; Hai-Ming Jin Department of Orthopaedics, The Second Affiliated Hospital and Yuying Children's Hospital of Wenzhou Medical University, 109\# Xueyuan Road, Wenzhou, Zhejiang 325027, People's Republic of China

$\mathrm{Tel}+86057788002814$

Fax +86057788002823

Email aiminwu@wmu.edu.cn;

kkjinhaiming@।26.com
Background: Low back pain (LBP) is a very common condition and leads to serious pain, disability, and price tag all over the world. Intervertebral disk degeneration (IDD) is one of the major reasons that contributed to LBP. The levels of interleukin 1 beta (IL-1 $\beta$ ) increase significantly in degenerative disks. IL-1 $\beta$ also accelerates IDD. Sinapic acid (SA) has the effect of anti-inflammatory, antioxidant and antimicrobial. However, the effect of SA on IDD has never been studied. Therefore, the aim of this study was to figure out whether SA has protective effect on nucleus pulposus (NP) cells and further explore the possible underlying mechanism.

Methods: The nucleus pulposus (NP) tissues of rats were collected and cultured into NP cells. The NP cells were stimulated by IL-1 $\beta$ and treated with SA. In vitro treatment effects were evaluated by ELISA, Western blot assay, immunofluorescence, TUNEL method and real-time PCR. We conducted percutaneous needle puncture in the rat tail to build intervertebral disk degeneration model and treated rats with SA. In vivo treatment effects were evaluated by hematoxylin and eosin (HE) and safranin $\mathrm{O}$ (SO) staining and magnetic resonance imaging (MRI) method.

Results: Our results showed that SA not only inhibited apoptosis but also suppressed inflammatory mediators including nitric oxide (NO), prostaglandin E2 (PGE2), cyclooxygenase 2 (COX-2), inducible nitric oxide synthase (iNOS) interleukin 6 (IL-6) and tumor necrosis factor alpha (TNF- $\alpha)$ in IL-1 $\beta$-stimulated NP cells. As to extracellular matrix (ECM), SA could increase collagen II and aggrecan levels and reduce the expression of MMP13 and ADAMTS5 during the stimulation of IL-1 $\beta$. Furthermore, SA could activate nuclear factor-erythroid 2-related factor-2 (Nrf2) to inhibit nuclear factor $\kappa \mathrm{B}(\mathrm{NF}-\kappa \mathrm{B})$ induced by IL-1 $\beta$. Nrf2 knockdown partly reduced the protective effect of SA on NP cells. Correspondingly, SA ameliorated IDD by promoting Nrf2 expression. In vivo results also showed that SA could delay the progression of IDD.

Conclusion: In conclusion, we demonstrated that SA could protect the degeneration of NP cells and revealed the underlying mechanism of SA on Nrf2 activation in NP cells.

Keywords: intervertebral disk degeneration, sinapic acid, apoptosis, Nrf2, inflammation

\section{Introduction}

Low back pain (LBP) is a very common condition and leads to serious pain, disability, and price tag all over the world. ${ }^{1-3}$ LBP was the fifth leading cause of disability-adjusted life years (DALYs) among American populations in 2016 and the first leading cause of years lived with disability (YLD). ${ }^{4,5}$ About $50-85 \%$ of the 
population has back pain at some point in their whole life. $^{6,7}$ Previous studies have shown intervertebral disk degeneration (IDD) is one of the major reasons that contributed to $\mathrm{LBP}^{8-10}$

Intervertebral disks are combined with three different tissues including the annulus fibrosus (AF), the nucleus pulposus (NP) and the endplates (EP) located above and below the NP. ${ }^{11}$ Extracellular matrix (ECM) produced by NP cells can sustains mechanical balance, so it is important in IDD. ${ }^{12,13}$ Previous studies pointed that inflammation and apoptosis are the leading causes of IDD. ${ }^{14,15}$ As IDD progressed, some inflammation cytokines such as interleukin 1 beta (IL-1 $\beta$ ) and tumor necrosis factor alpha (TNF- $\alpha$ ) will increase significantly. ${ }^{16}$ The excessive increase of inflammation cytokines can promote the degradation of collagen and aggrecan and the generation of matrix metalloproteinases (MMPs) which can promote the degradation of ECM. ${ }^{14,17}$ In addition, IL-1 $\beta$ also can induce several inflammatory mediators including cyclooxygenase 2 (COX-2), nitric oxide (NO), prostaglandin E2 (PGE2), NO synthase (NOS), a disintegrin and metalloproteinase thrombospondin motifs (ADAMTS). ${ }^{18}$ These inflammatory mediators can further impair the ECM. Increased proinflammation cytokines also promote apoptosis of NP cells, which contributes to the leakage of NP cells and the reduction in ECM synthesis. ${ }^{19}$ These results all can accelerate the process of IDD. Therefore, inhibiting the apoptosis, rebalancing NP microenvironment and reducing the excessive inflammation response can effectively treat and prevent IDD. Moreover, nuclear factor-erythroid 2-related factor-2 (Nrf2) has the effect of antioxidant and anti-inflammatory in many degenerative diseases. Previous studies pointed that activating the Nrf2/ HO-1 signaling pathway can inhibit NF- $\kappa$ B to NP cells. $^{20,21}$ So, promoting the expression of Nrf2 may be useful in treating IDD.

Sinapic acid (SA), having various biological activities, is widespread in the plant kingdom. It had been proved that SA has the effect of anti-inflammatory, antioxidant and antimicrobial. ${ }^{22-24}$ Previous studies showed that SA could suppress the inflammation response through $\mathrm{NF}-\kappa \mathrm{B}$ inactivation. $^{24,25}$ In addition, SA could lead to NF- $\kappa B$ inactivation by activating the Nrf2/HO-1 pathway. $^{26}$ However, the effect of SA on NP cell dysfunction has never been studied. Therefore, the aim of this study was to figure out whether SA has anti-apoptosis and antiinflammatory effects on IL-1 $\beta$-stimulated NP cells and further explore the possible underlying mechanism.

\section{Materials and Methods}

\section{Ethics Statement}

The protocol of this study was strictly in accordance with the principles of Animal Care and Use Committee of Wenzhou Medical University. This study was approved by Wenzhou Medical University (wydw2014-0129).

\section{Reagents and Antibodies}

Sinapic acid (purity $\geq 98 \%$ ), IL-1 $\beta$, dimethylsulfoxide (DMSO), collagenase II and carboxymethylcellulose were purchased from Sigma Chemical Co. (St. Louis, MO, USA). We dissolved SA into $0.5 \%$ carboxymethylcellulose sodium to product oral suspension. The primary antibodies against aggrecan, ADAMTS 5, collagen II, $\beta$ actin, MMP13, HO-1, Nrf2 and lamin B1 were acquired from Abcam (Cambridge, UK). The antibodies of Bax, Bcl-2, iNOS, COX-2, cleaved-caspase 3, p65 and $\mathrm{I} \kappa \mathrm{B} \alpha$ were purchased from CST (MA, USA). Second antibody, including Alexa Fluor 488 and 594, was purchased from Abcam. The 4',6-diamidino-2-phenylindole (DAPI) was acquired from Beyotime (Shanghai, China).

\section{Isolation and Culture of NP Cells}

Fifteen 4-weeks-years old SD rats were randomly selected and then euthanized by an overdose of sodium pentobarbital. NP tissues were collected from tails. Then, the tissues were digested by $0.1 \%$ collagenase II $(2 \mathrm{mg} / \mathrm{mL})$ for $4 \mathrm{~h}$ at $37^{\circ} \mathrm{C}$. The NP tissues were transferred into Dulbecco's modification of Eagle's medium (DMEM)/ F12 (Gibco, Invitrogen, Grand Island, NY) mixed with $15 \%$ fetal bovine serum (FBS; Gibco, Invitrogen, Grand Island, NY) and antibiotics (1\% penicillin/streptomycin) in the incubator at $5 \% \mathrm{CO} 2$ at $37^{\circ} \mathrm{C}$.

After incubation for $24 \mathrm{~h}$, the medium was first changed. When confluent, the NP cells were harvested by $0.25 \%$ Trypsin-EDTA (Gibco, Invitrogen). Next, NP cells were passed into $10-\mathrm{cm}$ culture plates with an appropriate density, approximately 120,000 cells a plate. The complete medium was changed every 2-3 days. We used the first two and three passage NP cells in our study.

\section{Cell Viability Analysis}

The cytotoxicity of SA on NP cells was determined by Cell Counting Kit-8 (CCK-8; Dojindo Co., Kumamoto, Japan) according to the protocol. NP cells were treated with SA for $24 \mathrm{~h}$ and then washed by phosphate-buffered saline (PBS) for one time. Next, $100 \mu \mathrm{L}$ DMEM/F12 
contained with $10 \mu \mathrm{L}$ CCK-8 solution was added to every well of the plate for $2 \mathrm{~h}$ at $37^{\circ} \mathrm{C}$. Finally, the absorbance was measured at $450 \mathrm{~nm}$ by using micro-plate reader. All experiments were performed three times.

\section{Immunofluorescence}

NP cells were seeded on slices in glass plates in a sixwell plate with the density of $3 \times 10^{5}$ cells $/ \mathrm{mL}$ and incubated for 48 hours. Glass coverslips with NP cells were washed three times in PBS before fixation using 4\% paraformaldehyde for 15 minutes and then followed with permeation using $0.5 \%$ Triton for 5 minutes at room temperature. Next, cells were blocked by $10 \%$ bovine serum albumin for $1 \mathrm{~h}$ at $37^{\circ} \mathrm{C}$. Cells were washed by PBS and incubated with primary antibodies including collagen II (1:200), P65 (1:200) and MMP-13 (1:200) in a humid chamber overnight at $4^{\circ} \mathrm{C}$. On the next day, NP cells were incubated with Alexa Fluor ${ }^{\circledR} 488$ labeled conjugated second antibodies $(1: 400)$ for $1 \mathrm{~h}$ at $37^{\circ} \mathrm{C}$. Then the nuclear was labeled by DAPI for $5 \mathrm{~min}$. Finally, images were captured by using fluorescence microscope, and then the quantification of fluorescence intensity was calculated by Image J software 2.1 (Bethesda, MDUSA) by double-blinded observers who did not know the experimental groups.

\section{Western Blot Assay}

The protein of NP cells was extracted using RIPA lysis buffer containing with $1 \mathrm{mM}$ PMSF (phenylmethanesulfonylfluoride). BCA Protein Assay Kit (Beyotime) was used to measure the concentration of protein. Next, sodium dodecyl sulfate-polyacrylamide gel electrophoresis (SDSPAGE) was used to separate the protein and then transferred to a polyvinylidene difluoride membrane (Bio-Rad, USA). After the PVDF membranes blocked with 5\% nonfat for 2 hours at room temperature, the membranes were incubated with the primary antibodies including iNOS (1:1000), COX-2 (1:1000), cleaved caspase 3 (1:1000), Nrf2 (1:500), HO-1 (1:5000), Lamin-B (1:1000), GADPH (1:1000), Bax (1:1000), Bcl-2 (1:1000), collagen II (1:1000), aggrecan (1:1000), ADAMTS-5 (1:1000), MMP13 (1:1000), IкB $\alpha(1: 1000)$ and p65 (1:1000) overnight at $4{ }^{\circ} \mathrm{C}$. Next day, the membranes were washed and incubated by secondary antibodies (1:3000) at room temperature. The blots were detected by electro chemiluminescence plus reagent (Invitrogen) and the intensity was quantified using Image Lab 3.0 software (Bio-Rad).

\section{TUNEL Method}

The NP cells adhered to glasses were fixed by $4 \%$ paraformaldehyde for $15 \mathrm{~min}$ and then washed by PBS three times. Next, NP cells were incubated with $0.1 \%$ Triton for $10 \mathrm{~min}$ at $4^{\circ} \mathrm{C}$. Then, NP cells were stained with in situ Cell Death Detection Kit (F. Hoffmann-La Roche Ltd., Basel, Switzerland) for one hour. Nuclear was stained with DAPI after washing for three times by PBS in the dark space. Finally, fluorescence microscope (Olympus) was used to observe apoptotic changes and images of apoptotic cells.

\section{Real-Time PCR}

To extract total RNA from NP cells, TRIzol method (Invitrogen, USA) was used. RNA was reversed to complementary DNA (cDNA) and cDNA was amplified by using Prime Script-RT Reagent Kit and SYBR Premix Ex Taq (Sangon, Shanghai, China). As previous study described, the $\Delta \Delta \mathrm{Ct}$ method was used to measure the expression of target genes in different groups. ${ }^{27}$ The primers of COX-2 (F) 5'-GAGAGATGTATCCTCCCAC AGTCA-3' (R) 5' -GACCAGGCACCAGACCAAAG-3'; IL-6 (F) 5'-GACAGCCACTCACCTCTTCA-3', (R) 5'TTCACCAGGCAAGTCTCCTC-3'; iNOS (F) 5'-CCT TACGAGGCGAAGAAGGACAG-3', (R) 5'-CAGTTTGA GAGAGGAGGCTCCG-3' and TNF- $\alpha$ (F) 5'-GTCAGA TCATCTTCTCGA ACC-3', (R) 5'-CAGATAGATGGGC TCATACC- $3^{\prime}$ refer to a previous study. ${ }^{28}$

\section{The Measurement of NO, PGE2, TNF- $\alpha$, and IL-6}

We obtained cells culture supernatants, and then we used Griess reagent to measure the NO level. Enzyme-linked immunosorbent assay (ELISA) Kits (R\&D Systems, Minneapolis, MN) was used to measure the level of TNF- $\alpha$, PGE2 and IL-6 according to the protocol. All experiments were conducted five times.

\section{Surgical Procedure}

Forty-five SD rats (about 200-250 g) were randomly classified into three groups which including control group $(n=12)$, IDD group (received a gavage of saline after surgery, $n=12$ ), and SA group (received a gavage of SA after surgery, $n=12$ ). IDD group and SA group rats were anesthetized by $2 \%(\mathrm{w} / \mathrm{v})$ pentobarbital $(40 \mathrm{mg} / \mathrm{kg})$. The specific level of rat-tail disc (Co7/8) was located by palpation on the coccygeal vertebrae and the disc location was confirmed with an X-ray radiograph. 
Needles (27 G) were applied to puncture the AF through the tail skin perpendicularly, and the depth of the puncture was $4 \mathrm{~mm}$ according to the previous study. ${ }^{29}$ Needles were held for $1 \mathrm{~min}$. After surgery, rats in SA group received a gavage of SA $(20 \mathrm{mg} / \mathrm{kg} /$ day $)$ and rats in IDD and control group received a gavage of $0.5 \%$ carboxymethylcellulose sodium every day until the rats were sacrificed.

\section{Hematoxylin and Eosin (HE) Staining and Safranin O-Fast Green Staining}

We harvested the intervertebral disks on 8 weeks postsurgery. The SD rats were sacrificed by injecting $10 \%$ pentobarbital for overdosage. The specimens were fixed in $4 \%$ paraformaldehyde for $48 \mathrm{~h}$ and then decalcified for more than one month. After that, we dehydrated and embedded in paraffin. The sample was cut into small sections with $5 \mu \mathrm{m}$ thick. HE and Safranin O-fast green staining was used to assess the level of disk degeneration. The cellularity and morphology of NP cells and the construction of intervertebral disk were assessed by three double-blinded histology professors by using a microscope (Leica). Then the histology score was assessed according to a grading scale as previous study described. ${ }^{30,31}$

\section{Magnetic Resonance Imaging (MRI)}

The rats were given the MRI examination at 8 weeks after surgery to evaluate the IDD. First, rats were anesthetized by intraperitoneal injection of $10 \%$ pentobarbital $(40 \mathrm{mg} /$ $\mathrm{kg}$ ). Then, rats were maintained at prone position for examination. The MRI mode was the finger-specific coil. 3.0 T MRI (Philips Intera Achieva 3.0MR) was examined for all rats to evaluate the structural and signal and changes in sagittal T2-weighted images. The degree of IDD was evaluated by Pfirrmann grading system. ${ }^{32}$

\section{Statistical Analysis}

All experiments were performed at least three times. The results were shown as mean \pm standard deviation (S.D). Data were analyzed by one-way analysis of variance (ANOVA) followed by the Tukey's test or $t$-tests for comparison between control and treatment groups. Categorical variables (Pfirrmann grading) were analyzed by the Kruskal-Wallis $H$-test. All statistical analysis was conducted in SPSS software (version 18; IBM Corp., USA). We considered $P$ value $<0.05$ as statistically significant.

\section{Results}

\section{Potential Cytotoxicity of SA and Its Role} as a Cytoprotectant in NP Cells

Figure 1A provides the chemical structure of SA (4-hydroxy3,5-dimethoxy cinnamic acid). The viability of NP cells was assessed by the CCK- 8 assay at different concentrations and the results are shown in Figure 1B. The viability of NP cells was unaffected when the concentration of SA was under 150 $\mu \mathrm{M}$. When we added both IL- $1 \beta$ and SA into NP cell medium, we found SA can partially reversed the effect of IL- $1 \beta$ (Figure 1C). Comprehensively analysis of these two results, we found that $50-100 \mu \mathrm{M}$ was the most effective concentration of SA to protect NP cells. Thus, we chose SA at concentrations of 50 and $100 \mu \mathrm{mol} / \mathrm{L}$ for further study.

\section{SA Protects NP Cells Against IL-I $\beta$ - Induced Apoptosis}

In degenerative NP tissues, the level of IL- $1 \beta$ which promotes the apoptosis increases significantly. ${ }^{33}$ In this study, we pretreated NP cells with SA and then treated with IL-1 $\beta$ for 24 $\mathrm{h}$ to simulate the inflammatory factors involved in IDD. The results of TUNEL showed that apoptosis increased during IL$1 \beta$ treatment in NP cells, but SA could partially decrease IL-
A

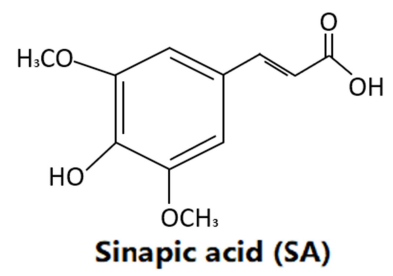
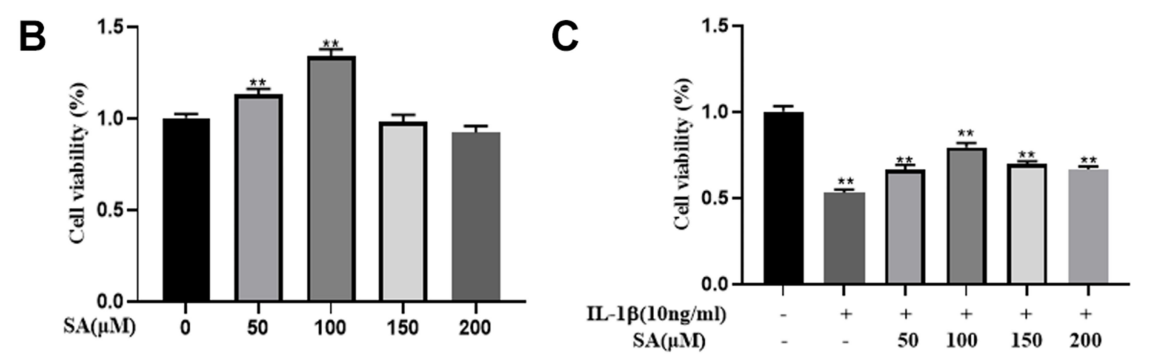

Figure I Effects of SA on the cell viability of nucleus pulposus (NP) cells. (A) Chemical structure of SA. (B) The cytotoxic effect of SA on NP cells was determined at various concentrations for $24 \mathrm{~h}$ using a CCK-8 assay. (C) The cytotoxic effect of SA on NP cells was determined at various concentrations with interleukin I beta (IL-I $\beta$ ) stimulation using a CCK-8 assay. All experiments were performed at least three times, and the data in the figures represent the mean \pm S.D. $* * P<0.0$ I compared with control group. 

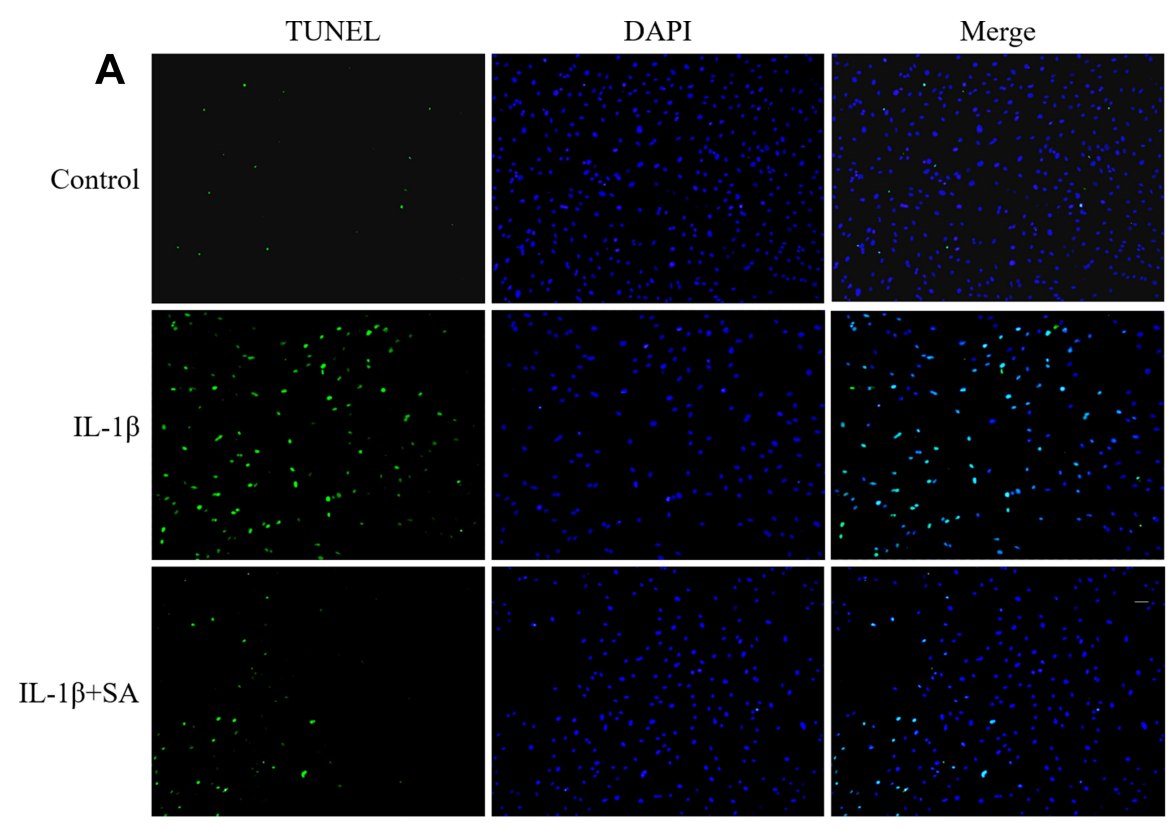

B
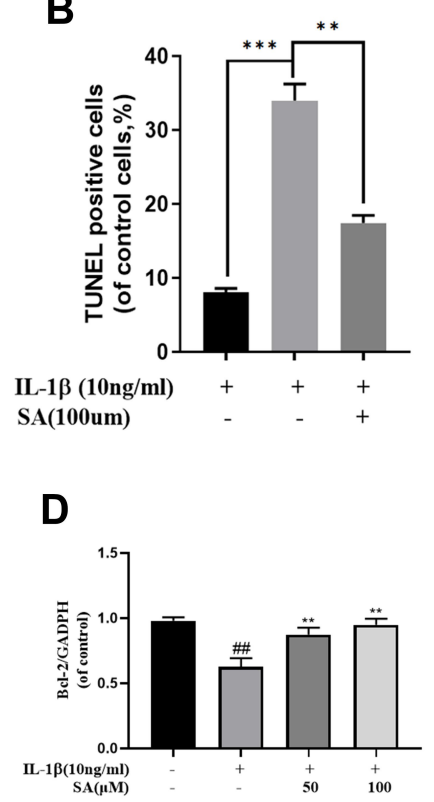

C

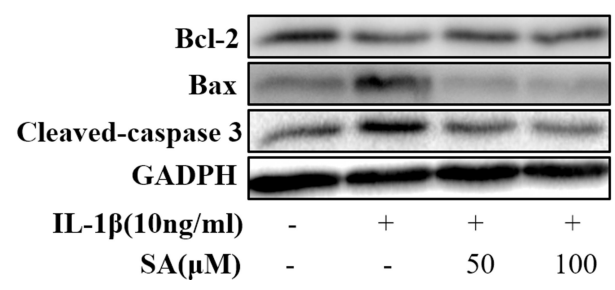

$\mathbf{F}$

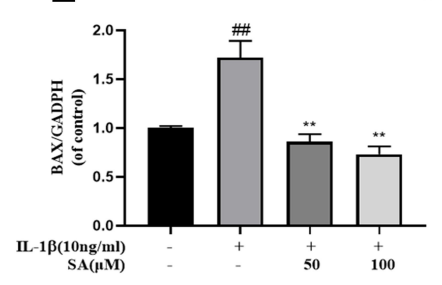

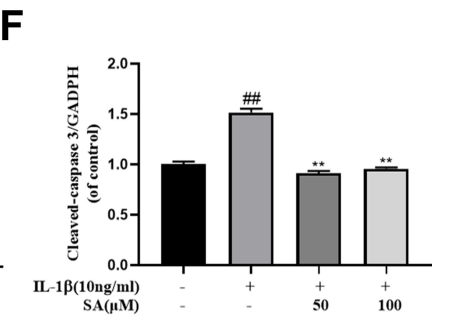

Figure 2 SA inhibit IL-I $\beta$ induced apoptosis in nucleus pulposus cells. NP cells treated with various concentration of SA for $24 \mathrm{~h}$ within IL-I $\beta$ stimulation. (A) Apoptosis cells were measured in nucleus pulposus cells by terminal deoxynucleotidyl transferase dUTP nick end labeling (TUNEL) Kit (original magnification $\times 200$ ). (B) Three images were randomly selected, and the number of cells with green fluorescence was quantified. (C) The protein expression of cleaved-caspase 3 , Bax, and Bcl-2 evaluated by Western blot in nucleus pulposus cells. (D-F) Quantification of immunoblots of cleaved-caspase 3, Bax, and Bcl-2, and each band was normalized to each individual sample's housekeeping gene. The experiment was repeated three times, with a representative example shown. All experiments were performed at least three times, and the data in the figures represent the mean \pm S.D. ${ }^{\#} \mathrm{P}<0.01$ compared with control group. $* * \mathrm{P}<0.01$ and $* * * \mathrm{P}<0.001$ compared with IL-I $\beta$ group.

$1 \beta$-induced apoptosis (Figure $2 \mathrm{~A}$ and $\mathrm{B} ; p<0.01$ ). The Western blot results also provided a similar result. When compared with IL-1 $\beta$-treated group, treating with SA could significantly increase the level of Bcl-2 (an anti-apoptotic protein) and reduce the levels of cleaved caspase 3 and Bax (both pro-apoptotic proteins) on NP cells (Figure 2C-F; $p<$ 0.01). Therefore, we can draw a conclusion that SA has an anti-apoptotic effect on NP cells.

\section{SA Inhibited the Expression Levels of iNOS, COX-2, PGE2, NO, TNF- $\alpha$, and IL- 6 in IL-I $\beta$-Stimulated NP Cells}

We further investigated the effect of SA on the production of COX-2 and inducible nitric oxide synthase (iNOS). We measured both the protein and mRNA levels of and COX-2 and iNOS by using reverse Western blot analysis and transcription-polymerase chain reaction (RT-PCR) analysis, respectively. We found that SA suppressed the expression of COX-2 and iNOS mRNA and protein on NP cells after stimulation of IL-1 $\beta$ (Figure 3A, B, E, F and G). The ELISA and RT-PCR analysis also pointed that SA inhibited the generation of interleukin-6 (IL-6) and TNF- $\alpha$ (Figure 3C, D, J and $\mathrm{K})$. Furthermore, SA also could suppress the production of NO and PGE2 (Figure 3H and I). In summary, the above results showed that SA inhibited the production of inflammatory cytokines and mediators. (All results' $p$ value $<0.01$ ).

\section{SA Protects NP Cells Against ECM Degradation Induced by IL-I $\beta$}

Then we researched the effect of SA in inhibiting ECM degradation. The Western blot results suggested that SA markedly inhibited IL-1 $\beta$-induced degeneration of main 
A

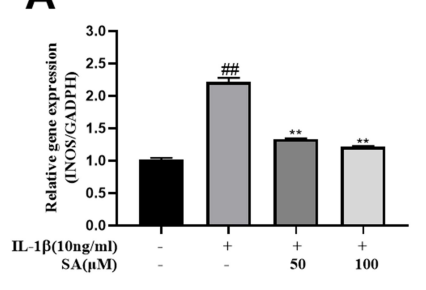

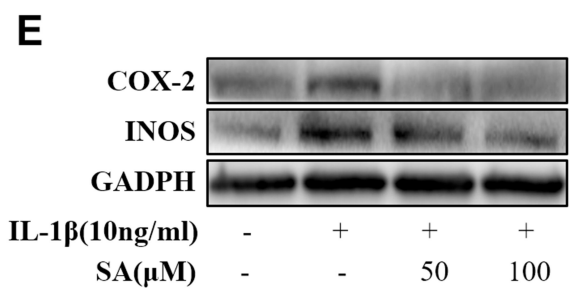

B

C

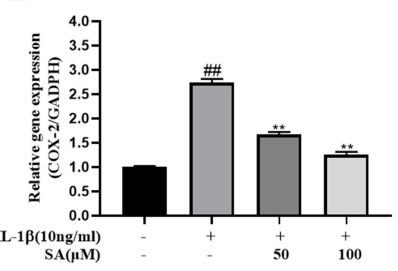

F

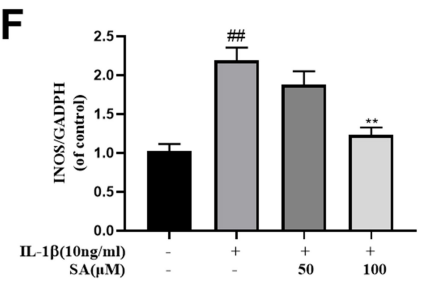

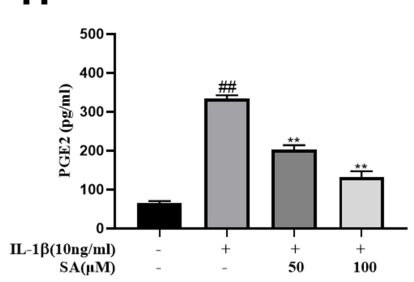

I

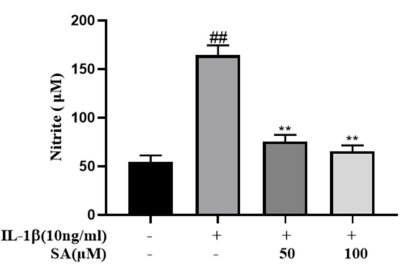

J

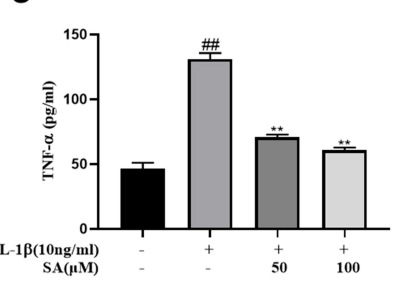

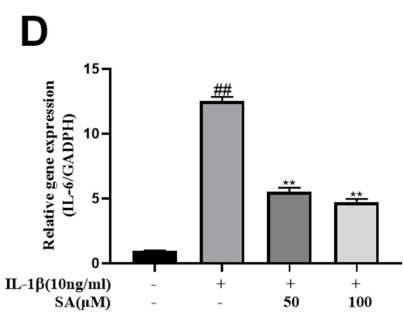

G

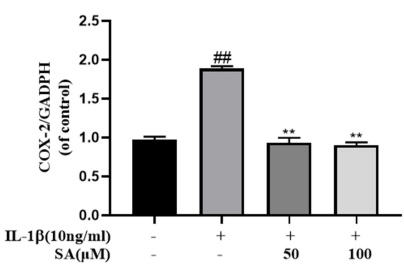

Figure $3 \mathrm{SA}$ inhibits inflammatory response in nucleus pulposus cells. Nucleus pulposus cells treated with various concentration of luteoloside for 24 h within IL-I $\beta$ stimulation. (A-D) The mRNA expressions of inducible nitric oxide synthase (iNOS), cyclooxygenase 2 (COX-2), tumor necrosis factor alpha (TNF- $\alpha$ ), and interleukin 6 (IL6) were measured by real-time Q PCR. (E) The protein expressions of iNOS and COX-2 in NP cells treated as above were evaluated by Western blot. (F-G) Quantification of immunoblots of iNOS and COX-2. The experiment was repeated at least three times, with a representative example shown. (H-K) IL-I $\beta$-induced PGE2, nitrite, TNF- $\alpha$, and IL-6 production were measured by ELISA with SA in a dose-dependent manner in NP cells. All experiments were performed at least three times, and the data in the figures represent the mean \pm S.D. ${ }^{\#} \mathrm{P}<0.01$ compared with control group. ${ }^{*} * \mathrm{P}<0.0 \mathrm{I}$ compared with IL-I $\beta$ group.

components of the ECM including collagen II and aggrecan (Figure 4A-C). The generation of MMP13 and ADAMTS5, which are involved in the degradation of the ECM (Figure $4 \mathrm{~A}, \mathrm{D}$ and $\mathrm{E} ; p<0.01)$. Furthermore, the immunofluorescence of collagen II and MMP13 showed that the above proteins were mainly localized at cytoplasm. After IL-1 $\beta$ treating, the fluorescence intensity of collagen II decreased, while that of MMP13 increased following. After treatment with SA, we could find the trend was partially reversed (Figure 4F-I; $p<0.01$ ). In general speaking, we found that SA promoted the synthesis and inhibited the degradation of the ECM against IL-1 $\beta$-induced IDD.

\section{SA Regulates IL-I $\beta$-Induced NF-אB Activation in NP Cells}

Previous studies pointed that IDD was associated with inflammation and NF- $\mathrm{B}$ was an important factor in the inflammation response. ${ }^{34,35}$ According to Western blot analysis, after IL-1 $\beta$ stimulating, we found the production of several inflammation-related proteins (eg, I $\mathrm{B} \alpha \alpha$ and NF- $\kappa \mathrm{B}(\mathrm{p} 65)$ ) increased. The degradation I $\mathrm{KB} \alpha$, an upstream target of $\mathrm{NF}-\kappa \mathrm{B}$, contributes to the activation of the NF- $\mathrm{B}$ pathway. As shown in Figure $5 \mathrm{~A}-\mathrm{C}$, stimulation of IL-1 $\beta$ increased the degradation of $\mathrm{I} \kappa \mathrm{B} \alpha$ in the cytoplasm of the NP cells and the expression of p65 in the nucleus. Furthermore, we found that SA could inhibit expression of $\mathrm{p} 65$ and $\mathrm{I} \kappa \mathrm{B} \alpha$ degradation of NP cells to inhibit the activation of NF- $\kappa B$. Besides, the results of immunofluorescence showed IL-1 $\beta$ stimulation increased nuclear translocation of p65 (Figure 5D). However, treatment with SA could significantly reverse this phenomenon (Figure $5 \mathrm{D}$ and $\mathrm{E})$. These findings suggest that SA significantly inhibited the activation of NF- $\kappa \mathrm{B}$ in NP cells.

\section{SA Regulates IL-I $\beta$-Induced NF-kB Activation and Apoptosis via Nrf2 Signaling in NP Cells}

The results of Western blot analysis revealed that SA increased the expression of HO-1 in the cytoplasm and the expression of $\mathrm{Nrf} 2$ in the nuclei. After stimulating by IL-1 $\beta$, there was no significant increase in the levels of Nrf2 and HO-1 (Figure 6A-C; $p>0.05$ ). After pre- 
A

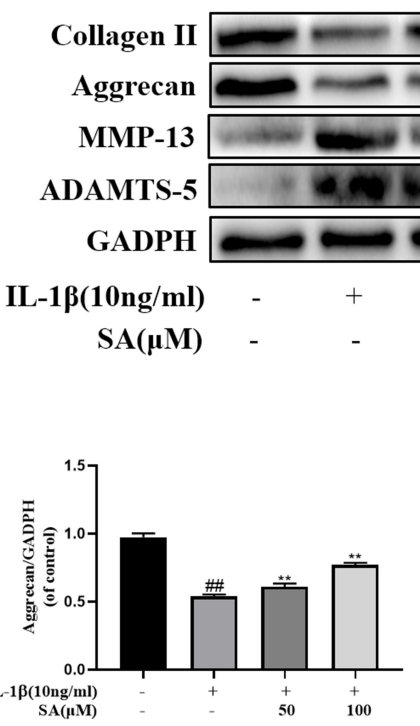

$\mathbf{F}$
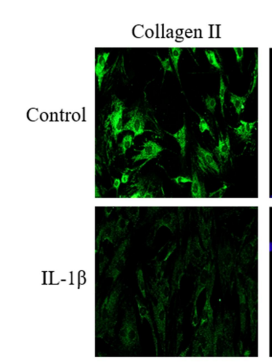

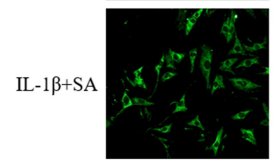

DAPI
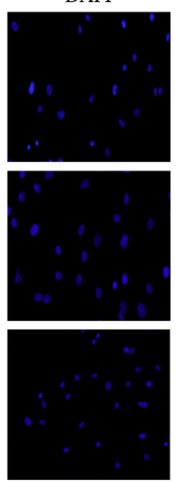

Merge
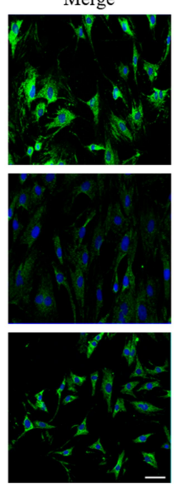

B

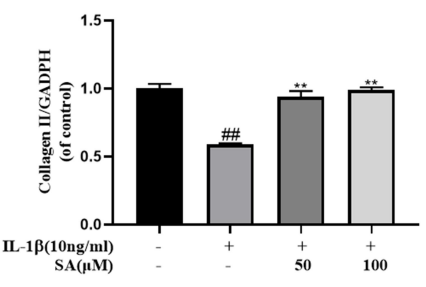

D

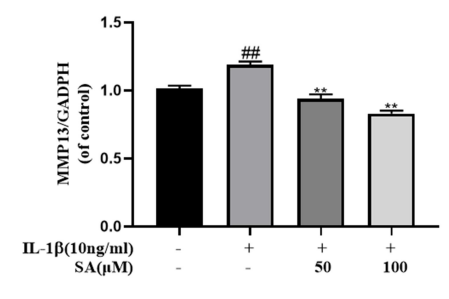

$\mathbf{G}$
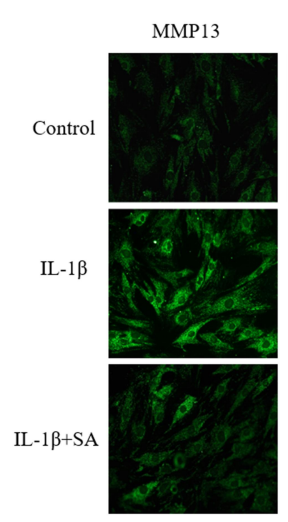

E

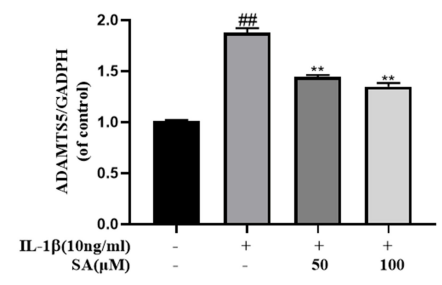

H

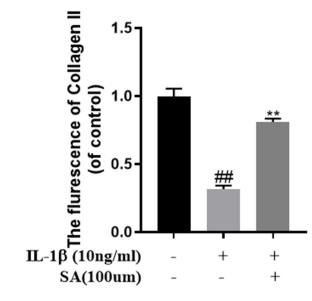

I

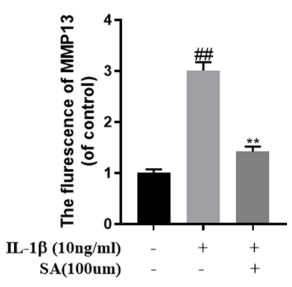

Figure 4 Effect of SA inhibit IL-I $\beta$ induced extracellular matrix degradation in nucleus pulposus cells. (A) Protein expressions of collagen II, aggrecan, MMPI3, and ADAMTS5 in NP cells treated as above were evaluated by Western blot. (B-E) Quantification of immunoblots of collagen II, aggrecan, MMPI3, and ADAMTS5. (F) The representative collagen II was detected by the immunofluorescence combined with DAPI staining for nuclei (original magnification $\times 400$, scale bar: $25 \mu$ m). (G) The representative MMPI3 were detected by the immunofluorescence combined with DAPI staining for nuclei (original magnification $\times 400$, scale bar: $25 \mu \mathrm{m}$ ). (H) The fluorescence intensity of collagen II was analyzed by Image J. (I) The fluorescence intensity of MMPI 3 was analyzed by Image J. All experiments were performed at least three times, and the data in the figures represent the mean \pm S.D. ${ }^{\#} \mathrm{P}<0.0 \mathrm{I}$ compared with control group. ${ }^{* *} \mathrm{P}<0.0 \mathrm{I}$ compared with IL-I $\beta$ group.

transfected with small interfering RNA for Nrf2 (Nrf2siRNA), the expression level of Nrf2 was significantly decreased, and the expression level of P65 was subsequently increased in the nuclei of the NP cells during stimulation with IL-1 $\beta$ (Figure 6D, F and G). Besides, in the NP cells which had been pre-transfected with Nrf2siRNA, the production of cleaved caspase 3 (a marker of apoptosis) markedly increased while the expression of HO-1 was significantly decreased (Figure $6 \mathrm{H}$ and I; $p<0.01)$. In conclusion, the $\mathrm{Nrf} 2 / \mathrm{HO}-1$ pathway is involved in SA induced apoptosis inhibition and $\mathrm{NF}-\kappa \mathrm{B}$ signaling suppression.

\section{SA Ameliorates IDD in a Puncture-Induced Rat Model}

We established an IDD rat model to assess the effects of $\mathrm{SA}$ on IDD in vivo. We used MRI to evaluate the degeneration degree of IDD in the rats. The MRI images showed that the disks of IDD group were inhomogeneous and with an intermittent gray signal intensity. However, the results of SA treated group showed a hyperintense white signals in the disks (Figure 7A). Furthermore, whether at 8 weeks, the Pfirrmann scores were significantly lower in the SA treated group when compared with IDD group (Figure 
A

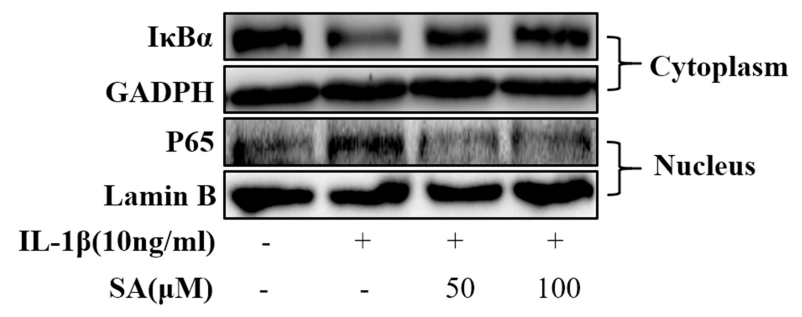

D
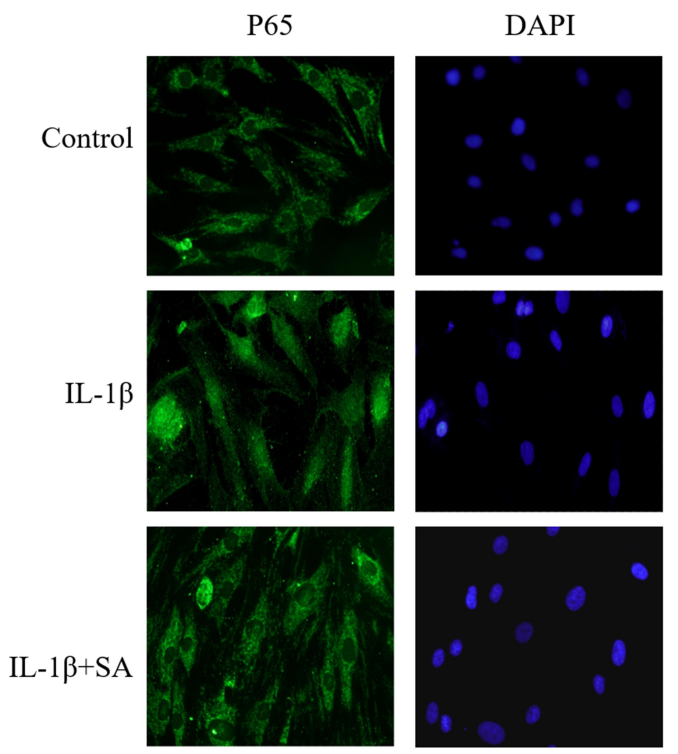

B

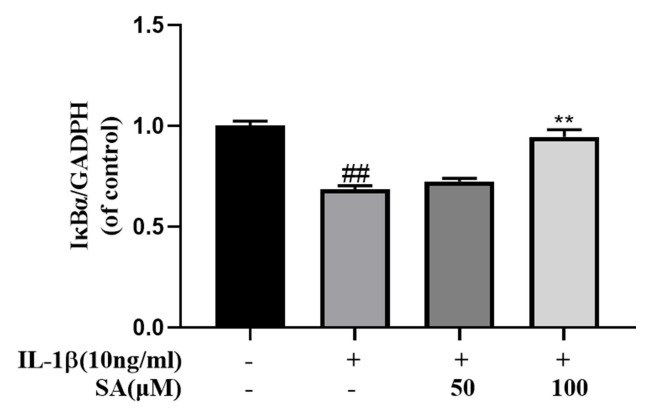

C

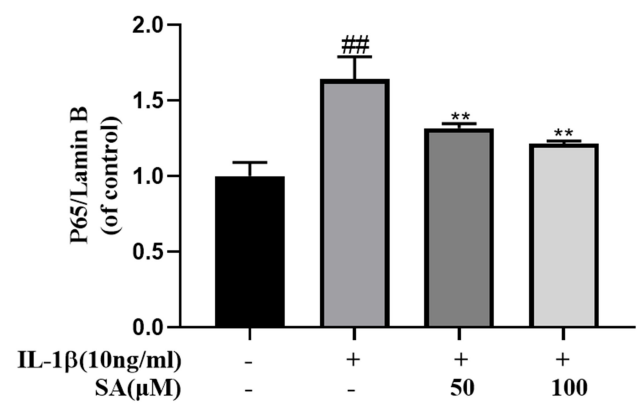

$\mathbf{E}$

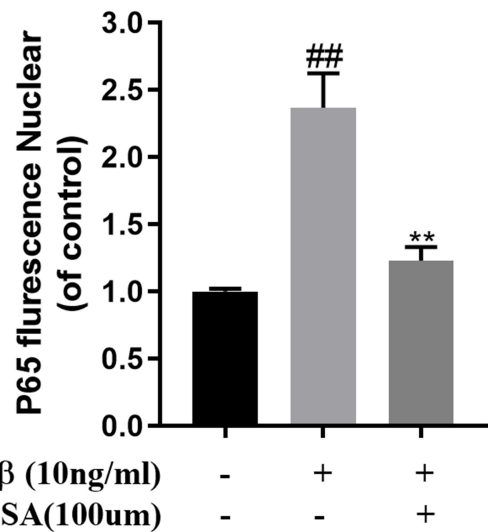

Figure 5 Effect of SA on IL-I $\beta$-induced NF-KB activation. NP cells were pretreated with SA for $24 \mathrm{~h}$ and then were treated with IL-I $\beta$ for another $24 \mathrm{~h}$. (A) The protein expressions of $I_{\kappa} B \alpha$ in cytoplasm and p 65 in nuclear in NP cells treated as above were visualized by Western blot. (B-C) Quantification of immunoblots of I $\kappa$ B $\alpha$ and p65. (D) The nuclei translocation of $\mathbf{p} 65$ was detected by the immunofluorescence combined with DAPI staining for nuclei (original magnification $\times 400$, scale bar: $25 \mu \mathrm{m})$. (E) Intensity of $\mathrm{p} 65$ in nuclear of NP cells was quantified. All experiments were performed at least three times, and the data in the figures represent the mean \pm S.D. ${ }^{\#} P<0.0$ I compared with control group. ${ }^{* * P}<0.01$ compared with IL-I $\beta$ group.

7C). As shown in Figure 7B, HE staining showed that the normal structure of the NP had almost gone in the IDD group. However, the normal structure and the shape of the NP tissues were still clearly visible in the SA group. As shown in the results of Safranin O (SO) stain, it was obvious that both the and the ECM and normal structure of the NP were better preserved in the SA group. The histologic score is shown in Figure 7D.

\section{Discussion}

IDD is significantly associated with an increased risk for LBP which was one of the most common causes of loss of labor capacity and quality of life. ${ }^{36-38}$ Therefore, it is urgent to figure out an effective therapy that delays or even reverses IDD. Due to inflammatory cytokines (eg, IL- $1 \beta$ ) play a critical role in the progression of IDD. ${ }^{39,40}$ In addition, many plant-derived compounds including SA have antioxidant and anti-inflammatory properties and with minor side effects. Therefore, in our study, we tried to demonstrate the superior effect of SA in treatment for IDD. The results showed that SA protected NP cells via the Nrf2/HO-1 signaling axis and ameliorates the progression of IDD in vivo (Figure 8).

According to recent studies, many critical factors are strongly associated with the progression of IDD, especially 
A

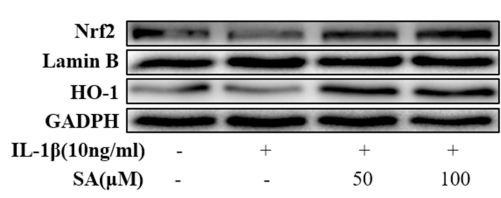

B

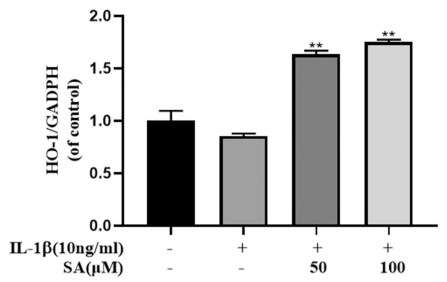

C

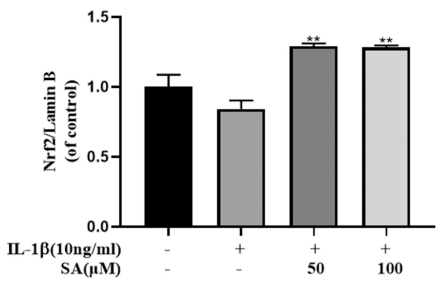

D

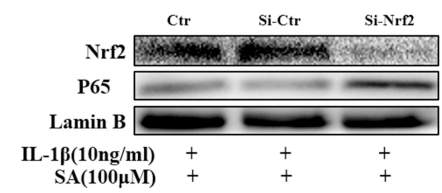

E

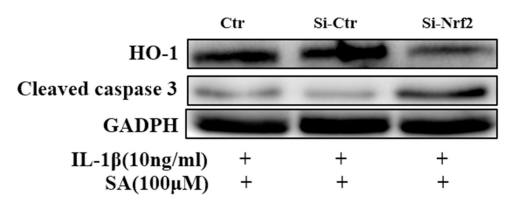

H

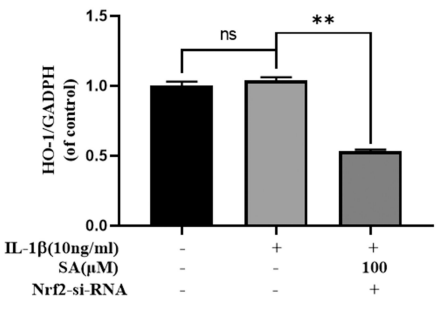

F

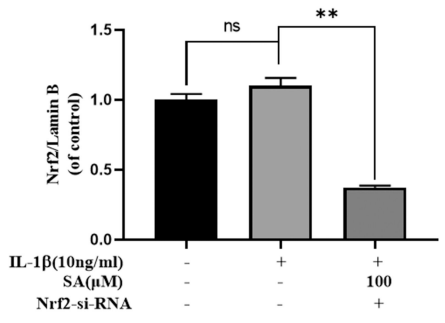

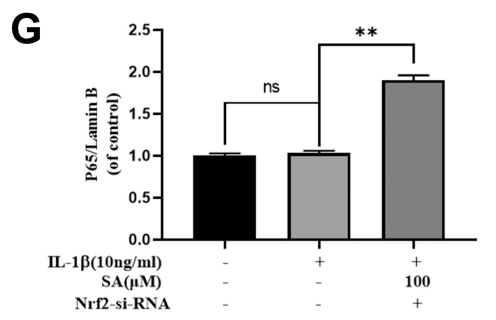

J
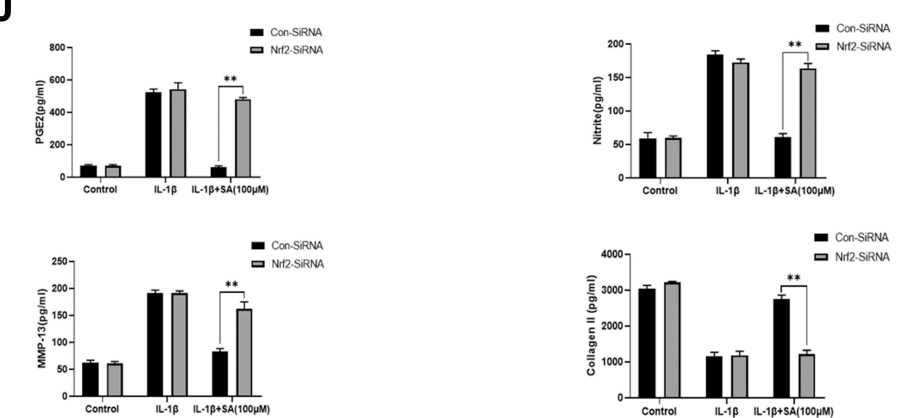

Figure 6 Effect of SA on nuclear factor (erythroid-derived 2)-like 2 (Nrf2)/HO-I pathway. (A) The protein expressions of Nrf2 in nuclear and HO-I in cytoplasm in NP cells treated as above were visualized by Western blot. (B and C) Quantification of immunoblots of Nrf2 and HO-I. (D and E) After Nrf2 knockdown, the protein expressions of Nrf2 and p65 in nuclear and HO-I and cleaved caspase 3 in cytoplasm in NP cells treated as above were visualized by Western blot. (F-I) Quantification of immunoblots of Nrf2, p65, HO-I, and caspase 3. (J) The production of PGE2, nitrite MMPI3 and collagen II was assessed by ELISA. All experiments were performed at least three times, and the data in the figures represent the mean \pm S.D. $* * P<0.01$ compared with IL-I $\beta$ group.

inflammation response, ECM degradation and apoptosis of NP cells. ${ }^{41,42}$ IL-1 $\beta$, one of the most important inflammation cytokines, is considered to cause and accelerate the progression of IDD. ${ }^{14}$ After we used IL- $1 \beta$ to stimulate the NP cells, we found that it could trigger the inflammation response, increase apoptosis of NP cells and promote the degeneration of the ECM. Besides, it also activated the NF- $\mathrm{KB}$ signaling pathway. Chen et al pointed that with the increase of apoptosis of NP cells, the synthesis of collagen II and aggrecan reduced, thereby accelerating the progression of IDD. ${ }^{29}$ Therefore, inhibiting excessive NP cell apoptosis could slow the progression of IDD. ${ }^{43,44}$ In this study, the results of TUNEL and Western blots showed that SA could reduce excessive apoptosis of NP cells.

Risbud et al pointed that the upregulated proinflammatory cytokines such as IL-1 $\beta$, TNF- $\alpha$ and IL-6 can lead to the progression of IDD. ${ }^{14}$ Besides, iNOS and COX-2 both could stimulate the generation of MMPs and accelerate the ECM degradation. ${ }^{27}$ So, the increase of TNF- $\alpha$, IL-6, iNOS and COX-2 in NP cells all can accelerate the development of IDD. In our study, we showed that SA can reduce the generation of TNF- $\alpha$, IL- 6 , iNOS 

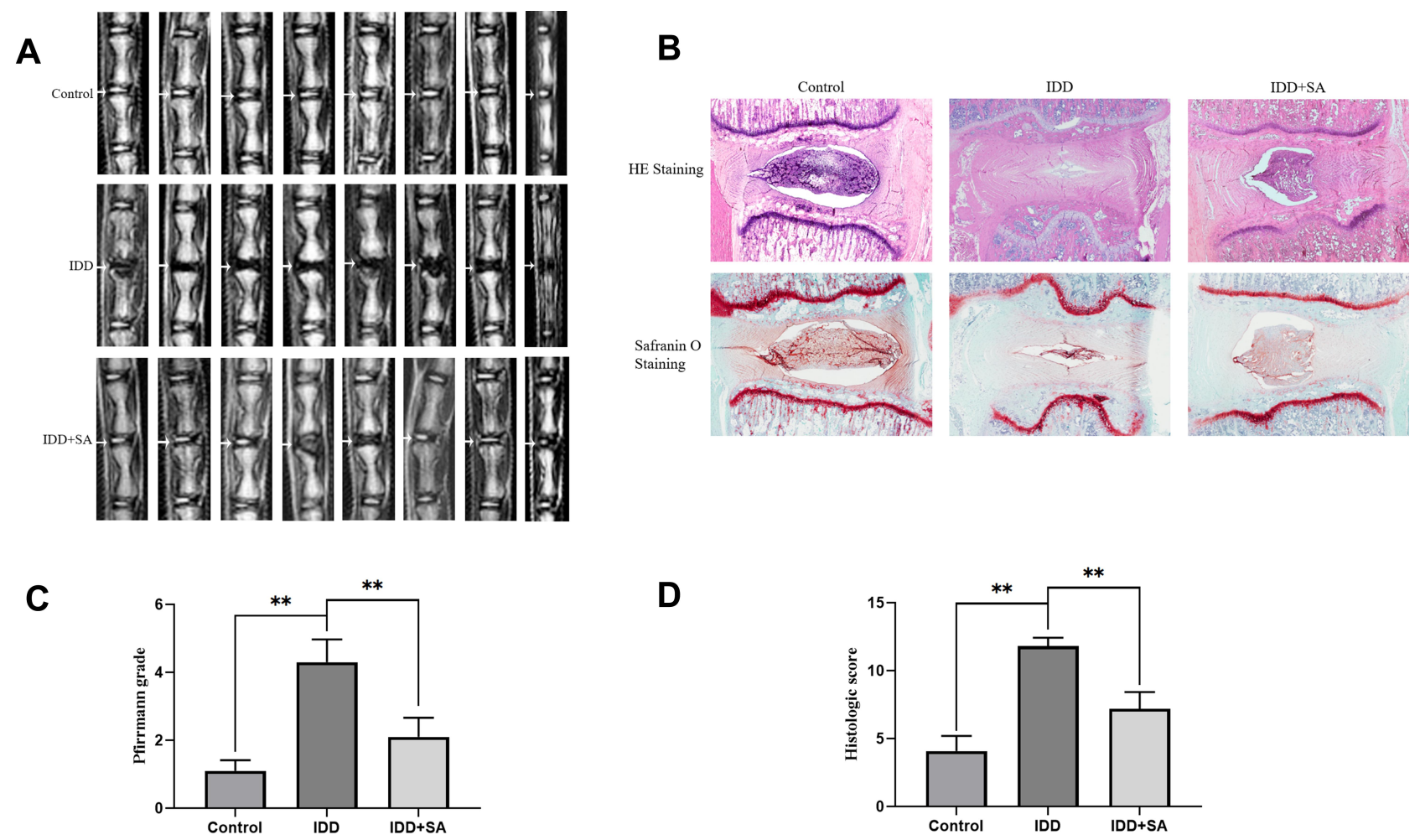

Figure $7 \mathrm{SA}$ treatment ameliorates rat intervertebral disk degeneration (IDD) in vivo. Rat IDD model was established by stabbing the whole layer of annulus fibrosus (AF) through the tail skin using needles (27G) for I min. Rats in SA group received a gavage of SA ( $20 \mathrm{mg} / \mathrm{kg} /$ day) and rats in IDD and control group received a gavage of $0.5 \%$ carboxymethylcellulose sodium every day until the rats were sacrificed. At 8-week degenerated disks were evaluated under MRI and stained with hematoxylin and eosin $(\mathrm{HE})$ and safranin $\mathrm{O}(\mathrm{SO})$. (A) T2-weighted MRI of a rat tail with a needle-punctured disk at 8 weeks post-surgery (white arrow: location of the needle-puncture disk). (B) Representative $\mathrm{HE}$ staining and SO staining of disk samples from different experimental groups at 8 weeks post-surgery (original magnification $\times 40$ ). Three sections were randomly selected for quantification, with a representative example shown. (C) The Pfirrmann MRI grade scores in three groups at week 8 . (D) The histological grades evaluated at 8 weeks post-surgery in three groups. All experiments were performed at least three times, and the data in the figures represent the mean \pm S.D. Significant differences between groups are indicated as $* * P<0.01$.

and COX-2 in NP cells to decrease the degradation of ECM during the stimulation of IL- $1 \beta$.

It is well known that activation of NF- $\mathrm{KB}$ signaling pathway is involving in the pathophysiological progression of IDD. $^{45,46}$ The NF- $\mathrm{KB}$ signaling pathway is involving in synthesis of pro-anabolic proteins (eg, aggrecan and collagen II) and proteinases in NP cells. ${ }^{47}$ The stimulation of IL-1 $\beta$ firstly triggers the release of phosphorylation of IкB $\alpha$ and p65 which translocated from the cytoplasm to the nucleus. NF- $\kappa \mathrm{B}$ is highly activated in the nucleus in diverse diseases. $\mathrm{NF}-\mathrm{kB}$ can promote the transcription of chemokines, adhesion molecules, proinflammatory cytokines, Cox-2, iNOS and MMPs, which can contribute to the decrease of the ECM. This study also revealed that SA inhibited NF- $\mathrm{KB}$ to reduces the generation of matrix-degrading proteases and inflammatory cytokines, mediators. More specifically, it was via the NF-kB signaling pathway.

Previous studies pointed that the Nrf2/HO-1 pathway plays a critical role in many inflammatory diseases. ${ }^{48,49}$ The absence of Nrf2 always increased the risk of inflammatory disorders. ${ }^{50}$ The level of $\mathrm{p} 65-\mathrm{NF}-\mathrm{\kappa B}$ protein increased significantly in Nrf2-deficient cells. ${ }^{51}$ Furthermore, Nrf2 can inhibit the activation of NF- $\mathrm{BB}$ pathway. A recent study pointed that Nrf2 activation could prevent IDD progress via inhibiting excessive apoptosis and inflammatory response. ${ }^{21}$ In the present study, we found SA inhibited the IL-1 $\beta$-induced excessive apoptosis and inflammatory response via the activation of Nrf2 in NP cells. In addition, the results of in vivo results also confirmed our above results that SA do prevent IDD progress.

In conclusion, the present study demonstrated that SA could protect NP cells by inhibiting inflammation response, apoptosis and ECM degradation in NP cells. SA also can maintain the normal structure of intervertebral disk in vivo. Besides, these protective effects of SA in NP cells were by activating the $\mathrm{Nrf} 2 / \mathrm{HO}-1$ signaling axis. Therefore, SA may be a natural and effective therapeutic medicine which can delay the progression of IDD. However, there was no effective therapeutic strategy for treating IDD nowadays. Our study showed that SA may be an effective therapeutic 


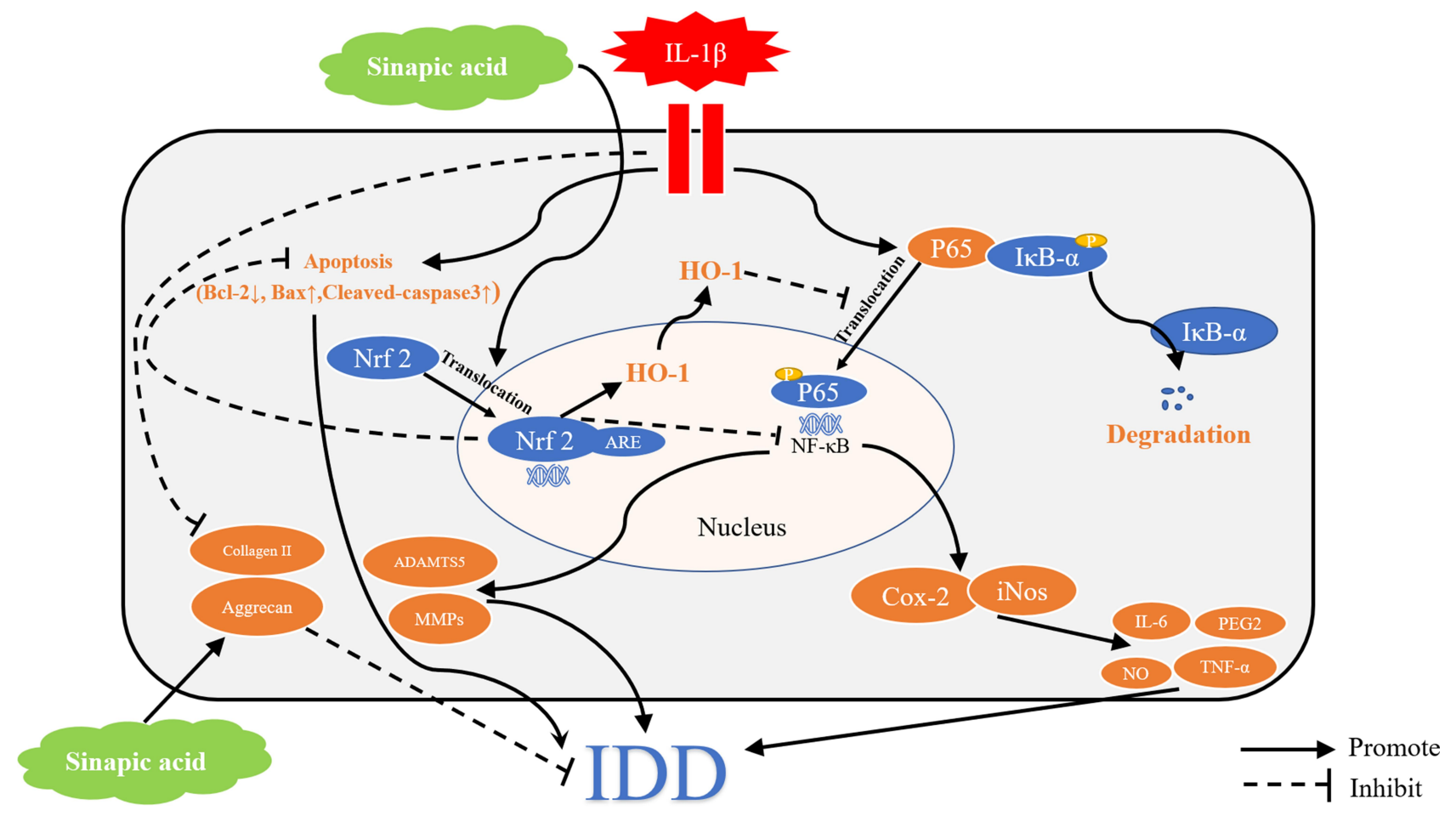

Figure 8 Potential molecular mechanism involved in SA treatment on NP cells. IL-I $\beta$ stimulation promotes inflammation response, apoptosis, and extracellular matrix (ECM) degradation through activation of NF- $\kappa B$ signaling pathway. SA treatment attenuated IL-I $\beta$-induced apoptosis through Nrf2 activation and attenuated inflammation

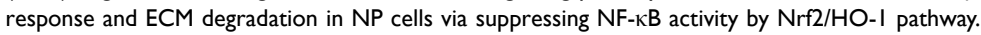

medicine for IDD treatment. Besides, our results also demonstrated that Nrf2 may be a promising candidate for treating IDD.

\section{Acknowledgments}

This work was funded by the Zhejiang Provincial Traditional Chinese Medicine Science and Technology Program (2020ZB146), National Natural Science Foundation of China (81501933), Wenzhou Municipal Science and Technology Bureau (Y20190018).

\section{Disclosure}

The authors declared that there is no conflict of interest in this work.

\section{References}

1. Murray CJ, Atkinson C, Bhalla K, et al. The state of US health, 1990-2010: burden of diseases, injuries, and risk factors. JAMA. 2013;310(6):591-608. doi:10.1001/jama.2013.13805

2. Maher C, Underwood M, Buchbinder R. Non-specific low back pain. Lancet. $\quad$ 2017;389(10070):736-747. doi:10.1016/S0140-6736(16) 30970-9

3. Jensen CE, Riis A, Petersen KD, Jensen MB, Pedersen KM. Economic evaluation of an implementation strategy for the management of low back pain in general practice. Pain. 2017;158(5):891-899. doi:10.1097/j.pain.0000000000000851
4. Mokdad AH, Ballestros K, Echko M, et al. The State of US health, 1990-2016: burden of diseases, injuries, and risk factors among US states. JAMA. 2018;319(14):1444-1472. doi:10.1001/jama.2018.0158

5. Wu A, March L, Zheng X, et al. Global low back pain prevalence and years lived with disability from 1990 to 2017: estimates from the Global Burden of Disease Study 2017. Ann Transl Med. 2020;8 (6):299. doi:10.21037/atm.2020.02.175

6. Fatoye F, Gebrye T, Odeyemi I. Real-world incidence and prevalence of low back pain using routinely collected data. Rheumatol Int. 2019;39(4):619-626. doi:10.1007/s00296-019-04273-0

7. Andersson GB. Epidemiological features of chronic low-back pain. Lancet. $\quad$ 1999;354(9178):581-585. doi:10.1016/S0140-6736(99) 01312-4

8. Lutz GK, Butzlaff M, Schultz-Venrath U. Looking back on back pain: trial and error of diagnoses in the 20th century. Spine. 2003;28(16):1899-1905. doi:10.1097/01.BRS.0000083365.41261.CF

9. Yelin E, Weinstein S, King T. The burden of musculoskeletal diseases in the United States. Semin Arthritis Rheum. 2016;46(3):259-260. doi:10.1016/j.semarthrit.2016.07.013

10. Scheele J, de Schepper EI, van Meurs JB, et al. Association between spinal morning stiffness and lumbar disc degeneration: the Rotterdam Study. Osteoarthritis Cartilage. 2012;20(9):982-987. doi:10.1016/j. joca.2012.05.011

11. Vergroesen PP, Kingma I, Emanuel KS, et al. Mechanics and biology in intervertebral disc degeneration: a vicious circle. Osteoarthritis Cartilage. 2015;23(7):1057-1070. doi:10.1016/j.joca.2015.03.028

12. Chen J, Xuan J, Gu YT, et al. Celastrol reduces IL-1 $\beta$ induced matrix catabolism, oxidative stress and inflammation in human nucleus pulposus cells and attenuates rat intervertebral disc degeneration in vivo. Biomed Pharmacother. 2017;91:208-219.

13. Liu W, Xia P, Feng J, et al. MicroRNA-132 upregulation promotes matrix degradation in intervertebral disc degeneration. Exp Cell Res. 2017;359(1):39-49. doi:10.1016/j.yexcr.2017.08.011 
14. Risbud MV, Shapiro IM. Role of cytokines in intervertebral disc degeneration: pain and disc content. Nat Rev Rheumatol. 2014;10 (1):44-56. doi:10.1038/nrrheum.2013.160

15. Ding F, Shao ZW, Xiong LM. Cell death in intervertebral disc degeneration. Apoptosis. 2013;18(7):777-785.

16. Wang $\mathrm{K}$, Chen T, Ying X, et al. Ligustilide alleviated IL-1 $\beta$ induced apoptosis and extracellular matrix degradation of nucleus pulposus cells and attenuates intervertebral disc degeneration in vivo. Int Immunopharmacol. 2019;69:398-407. doi:10.1016/j. intimp.2019.01.004

17. Cheng X, Zhang L, Zhang K, et al. Circular RNA VMA21 protects against intervertebral disc degeneration through targeting miR-200c and X linked inhibitor-of-apoptosis protein. Ann Rheum Dis. 2018;77 (5):770-779. doi:10.1136/annrheumdis-2017-212056

18. Molina-Holgado E, Ortiz S, Molina-Holgado F, Guaza C. Induction of COX-2 and PGE(2) biosynthesis by IL-1beta is mediated by PKC and mitogen-activated protein kinases in murine astrocytes. $\mathrm{Br}$ J Pharmacol. 2000;131(1):152-159. doi:10.1038/sj.bjp.0703557

19. Choi H, Tessier S, Silagi ES, et al. A novel mouse model of intervertebral disc degeneration shows altered cell fate and matrix homeostasis. Matrix Biol. 2018;70:102-122. doi:10.1016/j. matbio.2018.03.019

20. Zhang CX, Wang T, Ma JF, Liu Y, Zhou ZG, Wang DC. Protective effect of CDDO-ethyl amide against high-glucose-induced oxidative injury via the Nrf2/HO-1 pathway. Spine J. 2017;17(7):1017-1025. doi:10.1016/j.spinee.2017.03.015

21. Lin J, Chen J, Zhang Z, et al. Luteoloside inhibits IL-1 $\beta$-induced apoptosis and catabolism in nucleus pulposus cells and ameliorates intervertebral disk degeneration. Front Pharmacol. 2019;10:868. doi:10.3389/fphar.2019.00868

22. Chen C. Sinapic acid and its derivatives as medicine in oxidative stress-induced diseases and aging. Oxid Med Cell Longev. 2016;2016:3571614. doi:10.1155/2016/3571614

23. Lee JY. Anti-inflammatory effects of sinapic acid on 2,4,6-trinitrobenzenesulfonic acid-induced colitis in mice. Arch Pharm Res. 2018;41(2):243-250. doi:10.1007/s12272-018-1006-6

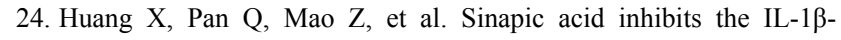
induced inflammation via MAPK downregulation in rat chondrocytes. Inflammation. 2018;41(2):562-568. doi:10.1007/ s10753-017-0712-4

25. Yun KJ, Koh DJ, Kim SH, et al. Anti-inflammatory effects of sinapic acid through the suppression of inducible nitric oxide synthase, cyclooxygase-2, and proinflammatory cytokines expressions via nuclear factor-kappaB inactivation. J Agric Food Chem. 2008;56 (21):10265-10272. doi:10.1021/jf802095g

26. Ansari MA. Sinapic acid modulates Nrf2/HO-1 signaling pathway in cisplatin-induced nephrotoxicity in rats. Biomed Pharmacother. 2017;93:646-653. doi:10.1016/j.biopha.2017.06.085

27. Tang Q, Feng Z, Tong M, et al. Piceatannol inhibits the IL-1 $\beta$ induced inflammatory response in human osteoarthritic chondrocytes and ameliorates osteoarthritis in mice by activating Nrf2. Food Funct. 2017;8(11):3926-3937. doi:10.1039/C7FO00822H

28. Zheng G, Zhan Y, Tang Q, et al. Monascin inhibits IL-1 $\beta$ induced catabolism in mouse chondrocytes and ameliorates murine osteoarthritis. Food Funct. 2018;9(3):1454-1464. doi:10.1039/ C7FO01892D

29. Chen D, Xia D, Pan Z, et al. Metformin protects against apoptosis and senescence in nucleus pulposus cells and ameliorates disc degeneration in vivo. Cell Death Dis. 2016;7(10):e2441. doi:10.1038/ cddis. 2016.334

30. Han B, Zhu K, Li FC, et al. A simple disc degeneration model induced by percutaneous needle puncture in the rat tail. Spine. 2008;33(18):1925-1934. doi:10.1097/BRS.0b013e31817c64a9

31. Mao HJ, Chen QX, Han B, et al. The effect of injection volume on disc degeneration in a rat tail model. Spine. 2011;36(16):E10621069. doi:10.1097/BRS.0b013e3182027d42
32. Pfirrmann CW, Metzdorf A, Zanetti M, Hodler J, Boos N. Magnetic resonance classification of lumbar intervertebral disc degeneration. Spine. 2001;26(17):1873-1878. doi:10.1097/00007632-20010901000011

33. Ito $M$, Yurube $T$, Kakutani $K$, et al. Selective interference of mTORC1/RAPTOR protects against human disc cellular apoptosis, senescence, and extracellular matrix catabolism with Akt and autophagy induction. Osteoarthritis Cartilage. 2017;25(12):2134-2146. doi:10.1016/j.joca.2017.08.019

34. Yao Z, Nie L, Zhao Y, et al. Salubrinal suppresses IL-17-induced upregulation of MMP-13 and extracellular matrix degradation through the NF-kB pathway in human nucleus pulposus cells. Inflammation . 2016;39(6):1997-2007. doi:10.1007/s10753-016$0435-\mathrm{y}$

35. Li Z, Wang X, Pan H, et al. Resistin promotes CCL4 expression through toll-like receptor-4 and activation of the p38-MAPK and NF$\kappa \mathrm{B}$ signaling pathways: implications for intervertebral disc degeneration. Osteoarthritis Cartilage. 2017;25(2):341-350. doi:10.1016/j. joca.2016.10.002

36. Luoma K, Riihimäki H, Luukkonen R, Raininko R, Viikari-Juntura E, Lamminen A. Low back pain in relation to lumbar disc degeneration. Spine. 2000;25(4):487-492. doi:10.1097/00007632-200002150-00016

37. Vos T, Allen C, Arora M, et al. Global, regional, and national incidence, prevalence, and years lived with disability for 310 diseases and injuries, 1990-2015: a systematic analysis for the Global Burden of Disease Study 2015. Lancet. 2016;388(10053):1545-1602.

38. Teraguchi M, Yoshimura N, Hashizume $\mathrm{H}$, et al. Prevalence and distribution of intervertebral disc degeneration over the entire spine in a population-based cohort: the Wakayama Spine Study. Osteoarthritis Cartilage. 2014;22(1):104-110. doi:10.1016/j. joca.2013.10.019

39. Le Maitre CL, Freemont AJ, Hoyland JA. The role of interleukin-1 in the pathogenesis of human intervertebral disc degeneration. Arthritis Res Ther. 2005;7(4):R732-745. doi:10.1186/ar1732

40. Lee JM, Song JY, Baek M, et al. Interleukin-1 $\beta$ induces angiogenesis and innervation in human intervertebral disc degeneration. J Orthopaed Res. 2011;29(2):265-269. doi:10.1002/jor.21210

41. Fontana G, See E, Pandit A. Current trends in biologics delivery to restore intervertebral disc anabolism. Adv Drug Deliv Rev. 2015;84:146-158. doi:10.1016/j.addr.2014.08.008

42. Yang H, Tian W, Wang S, et al. TSG-6 secreted by bone marrow mesenchymal stem cells attenuates intervertebral disc degeneration by inhibiting the TLR $2 / \mathrm{NF}-\kappa \mathrm{B}$ signaling pathway. Lab Invest. 2018;98(6):755-772. doi:10.1038/s41374-018-0036-5

43. Zhao CQ, Wang LM, Jiang LS, Dai LY. The cell biology of intervertebral disc aging and degeneration. Ageing Res Rev. 2007;6 (3):247-261. doi:10.1016/j.arr.2007.08.001

44. Wu X, Liu Y, Guo X, et al. Prolactin inhibits the progression of intervertebral disc degeneration through inactivation of the NF- $\mathrm{KB}$ pathway in rats. Cell Death Dis. 2018;9(2):98. doi:10.1038/s41419017-0151-Z

45. Li Z, Zhang K, Li X, et al. Wnt5a suppresses inflammation-driven intervertebral disc degeneration via a TNF- $\alpha / \mathrm{NF}-\mathrm{\kappa B}-\mathrm{Wnt} 5$ a negativefeedback loop. Osteoarthritis Cartilage. 2018;26(7):966-977. doi:10.1016/j.joca.2018.04.002

46. Zhongyi S, Sai Z, Chao L, Jiwei T. Effects of nuclear factor kappa B signaling pathway in human intervertebral disc degeneration. Spine. 2015;40(4):224-232. doi:10.1097/BRS.0000000000000733

47. Vincenti MP, Brinckerhoff CE. Transcriptional regulation of collagenase (MMP-1, MMP-13) genes in arthritis: integration of complex signaling pathways for the recruitment of gene-specific transcription factors. Arthritis Res. 2002;4(3):157-164. doi:10.1186/ar401

48. Kensler TW, Wakabayashi N, Biswal S. Cell survival responses to environmental stresses via the Keap1-Nrf2-ARE pathway. Annu Rev Pharmacol Toxicol. 2007;47:89-116. doi:10.1146/annurev. pharmtox.46.120604.141046 
49. Wardyn JD, Ponsford AH, Sanderson CM. Dissecting molecular cross-talk between Nrf2 and NF- $\mathrm{kB}$ response pathways. Biochem Soc Trans. 2015;43(4):621-626. doi:10.1042/BST20150014

50. Khan NM, Ahmad I, Haqqi TM. Nrf2/ARE pathway attenuates oxidative and apoptotic response in human osteoarthritis chondrocytes by activating ERK1/2/ELK1-P70S6K-P90RSK signaling axis. Free Radic Biol Med. 2018;116:159-171. doi:10.1016/j. freeradbiomed.2018.01.013
51. Cuadrado A, Martín-Moldes Z, Ye J, Lastres-Becker I. Transcription factors NRF2 and NF- $\mathrm{kB}$ are coordinated effectors of the Rho family, GTP-binding protein RAC1 during inflammation. J Biol Chem. 2014;289(22):15244-15258. doi:10.1074/jbc.M113.540633

\section{Publish your work in this journal}

The Journal of Inflammation Research is an international, peerreviewed open-access journal that welcomes laboratory and clinical findings on the molecular basis, cell biology and pharmacology of inflammation including original research, reviews, symposium reports, hypothesis formation and commentaries on: acute/chronic inflammation; mediators of inflammation; cellular processes; molecular mechanisms; pharmacology and novel anti-inflammatory drugs; clinical conditions involving inflammation. The manuscript management system is completely online and includes a very quick and fair peerreview system. Visit http://www.dovepress.com/testimonials.php to read real quotes from published authors.

Submit your manuscript here: https://www.dovepress.com/journal-of-inflammation-research-journal 